\title{
Effect of Matrix Rhythm Therapy versus Interferential current therapy with Laser therapy on plantar heel pain: A randomized clinical trial
}

\author{
Ketan Kirtikumar Bhatikar
}

\begin{abstract}
:
Background: Heel pain is a highly prevalent problem in most developing and under-developing countries. There are many studies done that show beneficial effects by different manual and physical modalities and therapies yet there is more of research to be done on new modalities and therapies that are drug-free rapid in its effect. Objectives: The purpose of this study was to evaluate and compare the effect of matrix rhythm therapy with strengthening exercises v/s interferential current therapy (ICT) with laser therapy and strengthening exercise. Methods: 30 participants with the age group 30 to 50 years old, experienced heel pain at least of one-month duration were randomly assigned to receive matrix rhythm therapy v/s ICT and LASER therapy. Strengthening exercises for plantar fascia were the same for both the groups. Intervention for both the groups was given alternatively for 15 sessions at the center by a certified therapist. Visual Analogue Scale (VAS) for the early morning first step pain and stiffness and Planter Fasciitis Pain/Disability Scale and revised Foot Function Index (FFI). Results: The pain subscale scores of the FFI showed significantly better results for the patients managed with the matrix rhythm therapy. Analysis of the response rates to the outcome measures also revealed significant differences with respect to pain, activity limitations, and patient satisfaction, with greater improvement seen in the group managed with the matrix rhythm therapy strengthening exercise. Conclusion: In the present study both the therapies showed the beneficial effects. However, matrix rhythm therapy was more significant than IFT and Laser therapy.
\end{abstract}

Keywords: Matrix Rhythm Therapy, Interferential Current Therapy, Laser Therapy, Heel Pain.

\section{INTRODUCTION:}

Plantar heel pain is the most commonly experienced pain under the heel of the foot and sometimes extending up to the medial arch. Pain causes soreness or tenderness of the sole which often radiates from the central part of the heel pad or the medial tubercle of the calcaneus bone that may cause substantial disability and poor health-related quality of life ${ }^{(1-3)}$. There is no exact cause found up to date. Most commonly reported risk factors suggested by most clinical and research expertise include being overweight, prolonged standing, pronated foot posture, having a reduced range of motion in the ankle and first metatarsophalangeal joint and older age. According to a recent study, the most common diagnosis is plantar fasciitis, which leads to medial plantar heel pain with the first weight-bearing steps after rest. Other causes of plantar heel pain include calcaneal stress fractures which progressively worsens pain after an increase in activity or change to a harder walking surface, nerve entrapment or neuroma (pain accompanied by tingling, burning, or numbness), heel pad syndrome (deep, bruise-like pain in the middle of the heel), and plantar warts. Achilles tendinopathy causes posterior heel pain or pain localized to the insertion site of the affected tendon. Tarsal tunnel syndrome, Haglund deformity are other common causes for heel pain ${ }^{(4)}$. A recent study was done to see the changes in woman's using high heels suggested that changing from flat footwear to high heels induces chronic muscle shortening associated with discomfort, reduced shock absorption, fatigue, and increased risk of misbalance and fall leading to ankle and other serious injuries. The study also suggests that in chronic adaptation to any function movement by muscles gradually adjusts to its new functional length by a chronic loss of sarcomeres in series that may lead to farther complications of that joint like reduce joint freedom of movement ${ }^{(5)}$. This also holds true in other conditions like sudden overweight, prolonged standing, paralysis, muscular atrophy, and muscular dystrophy etc. About 118 out of 200 patients have heel pain of which $60 \%$ in are females. The most common age group seems to be in 40 to 50 years ${ }^{(6-9)}$.

Heel pain is a very common problem in most of the working group and affects the daily living of the person.

Corresponding author: Ketan Kirtikumar Bhatikar. SPARC - Sport Physiotherapy Aqua Rehabilitation Centre. Ponda-Goa, India. Address: Shop 9 and 10, Taraangan, Near Civil Court, Ponda-Goa, 403401. Email: ketanbhatikar@gmail.com

1 SPARC - Sport Physiotherapy Aqua Rehabilitation Centre. Ponda-Goa, India.

Financial support: nothing to declare.

Submission date 21 September 2018; Acceptance date 07 June 2019; Publication date 20 September 2019 
Psychologically long-term heel pain can cause depression, anxiety and stress and have been shown to affect pain and disability ${ }^{(10)}$. Many studies have shown significant results in treatment with heel pain. Injections, insoles, heel pads, strapping, taping and surgery have been common forms of treatment offered. Other physical treatments may consider as therapies that include the use of electromedical devices delivering heat, electricity, magnetic fields, shockwave therapy; dry needling therapies, acupuncture ${ }^{(11-14)}$. According to Dr. Randoll, Matrix-Rhythm-Therapy (MRT) is a method to maintain the body's good health (prevention) and to support the healing of muscular-skeletal problems, post-operatively as well as rehabilitative. Normal cells are rhythmically vibrating between $8-12 \mathrm{~Hz}$. When any cell is injured or suffering any injury its oscillations decreases leading to obstruction in the healing process. The MRT is known to delivers physiological rhythmic oscillations between 8-12 Hz that Synchronizes with internal body rhythm and helps in the healing process at microcellular level ${ }^{(15,16)}$. Laser therapy uses light to penetrate the skin into tissues. It has been shown to aid in pain relief, stimulates wound healing, reduces inflammation, increases blood flow, reduces scarring, and stimulate tissue regeneration. Many types of research have proved that laser therapy can be a powerful anti-inflammatory that is equally effective in anti-inflammatory medications ${ }^{(17-19)}$. Interferential Current therapy (ICT) is an effective therapy option used in combination with other therapies in physiotherapy treatment. The IC device transmits electrical impulses in minute quantities through the skin to underlying tissue and nerves that are stimulated the healing properties. Frequencies produced by the ICT have been proven to stimulate endorphins, the body's natural painkillers that help to create a self-healing process without the need for medications. This form of therapy is useful in reducing pain, inflammation, curing edema, and spasms $s^{(20,21)}$. Therefore, the hypothesis to be tested in the present study was to evaluate the effect of MRT in the treatment of heel pain and to promote healing. Two groups of the same group matched subjects were tested - Group A with MRT followed by exercise therapy and Group B with ICT along with laser and exercise therapy.

\section{METHODS:}

Study design: the present study was a randomized clinical trial that studied the effect of MRT followed by exercise therapy and ICT along with laser and exercise therapy. Approval for the project was obtained from the head of Dr. K.B. SPARC Research management. Written consent was obtained prior to the study participants. Participants after their enrollment were randomly allocated to either (1) Group A receiving MRT followed by exercise therapy or (2) Group B receiving ICT along with laser and exercise therapy.

Participant: Participants of either gender with non-specific heel pain were recruited from Dr. K.B SPARC centers in Ponda and Margao Goa. Participants were included if they were suitable according to the inclusion criteria: 1) participants of both sex with the age group of 30 to 50 years. 2) Diagnose cause of heel pain may be plantar fasciitis having tenderness to pressure at the origin of the plantar fascia. 3) Heel pain greater than or equal to 3 on a 1-10 Visual analogue scale (VAS). Participants were excluded from the study statistics on the following exclusion criteria. Exclusion criteria: 1) having any history fracture or surgery in ankle and foot. 2) Any muscle stress or strain injury. 3) Any metabolic or connective disorders or associated disorders that interfere with the treatment protocol. 32 participates were evaluated by the clinic where 28 participants were included in the inclusion and exclusion criteria and randomly allocated to both the groups (Figure 1).

Primary outcome: In the present study we evaluated the first step pain in the morning experienced by the patients. First step pain was recorded by using $\mathrm{VAS}^{(22)}$. We also considered planter fasciitis pain/disability scale as our primary evaluating outcome measure. Plantar Fasciitis Pain/Disability Scale (PFPS) evaluates two components; one for the pain severity and

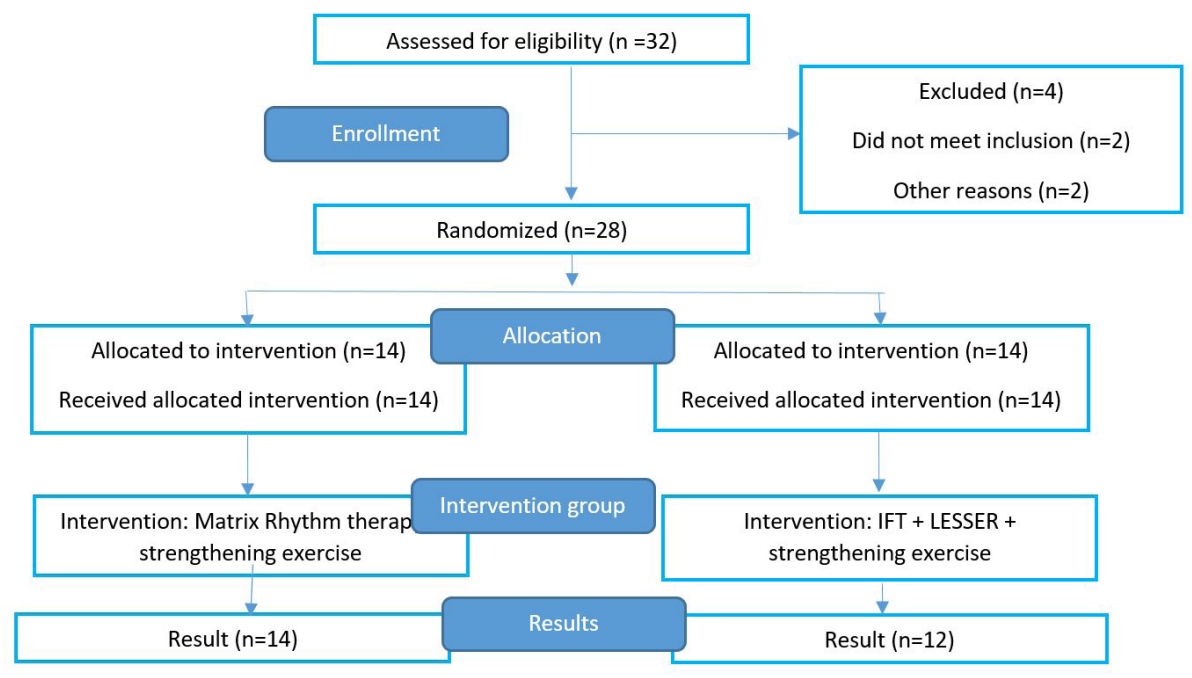

Figure 1. Patient distribution flow chart. 


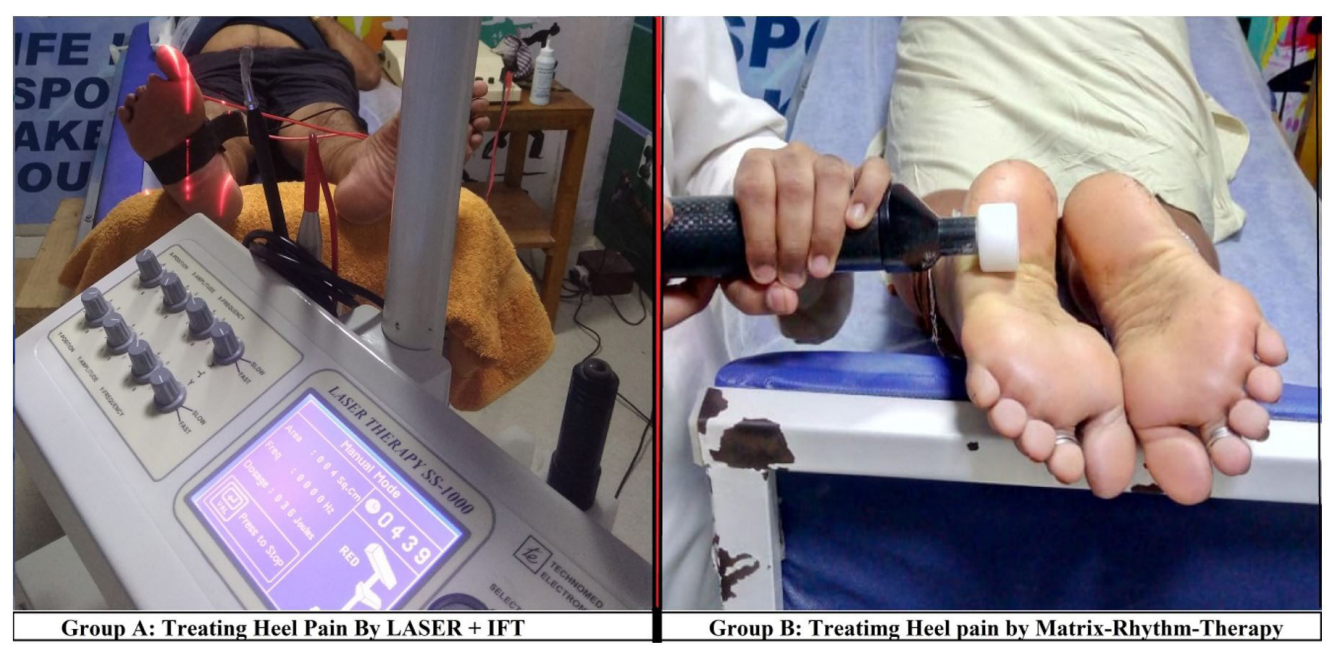

Figure 2. Treatment modalities used in Group A and Group B for treating Heel Pain.

impact on functional abilities, due to Plantar Fasciitis. Studies also demonstrated that PFPS is effective in differentiating between plantar fasciitis patient's $v / s$ patients with other pathologies causing heel pain. PFPS shows higher the score the worse is the condition ${ }^{(23,24)}$.

Secondary outcome: In the present study we used revised foot functional index (FFI-R) which is a self-administered questionnaire and can be used to evaluate the extent of foot pain and stiffness, the effect on daily food-related activities, and the quality of life. Test-retest reliability of the Foot Functional Index (FFI) total and subscale scores range from 0.87 to 0.69 , while internal consistency ranged from 0.96 to 0.73 . Original FFI contains 23 items were revised extensive version FFI-R contains 68 items $^{(25,26)}$. In 2006, the FFI was on the basis of criticisms from researchers and clinicians. It contains 4 subscales and 68 items. Both the FFI short and long from demonstrated good psychometric properties.

\section{PROCEDURE:}

After inform consent was signed by all the subjects, patients were randomly allocated in two groups, namely group A and Group B. before starting of the study subjects have explained the procedure and benefits of the study. Also were advised not to be on any medication that interferes with the result and effect of the undergoing study. Subject pre-session records were maintained. In Group A subjects were treated with ICT followed by laser and strengthening exercises (Figure 2A). In Group B patient was treated with 45 minutes of MRT followed by conventional strengthening exercises (Figure 2B). At the end of the 15 sessions, post-session measures were recorded and detailed statistical evaluation was done (Figure 3). Strengthening exercise for both the groups ware stared 3rd session onwards. 1) plantar-specific stretching and calf stretching 2) resisted plantar and calf musculature

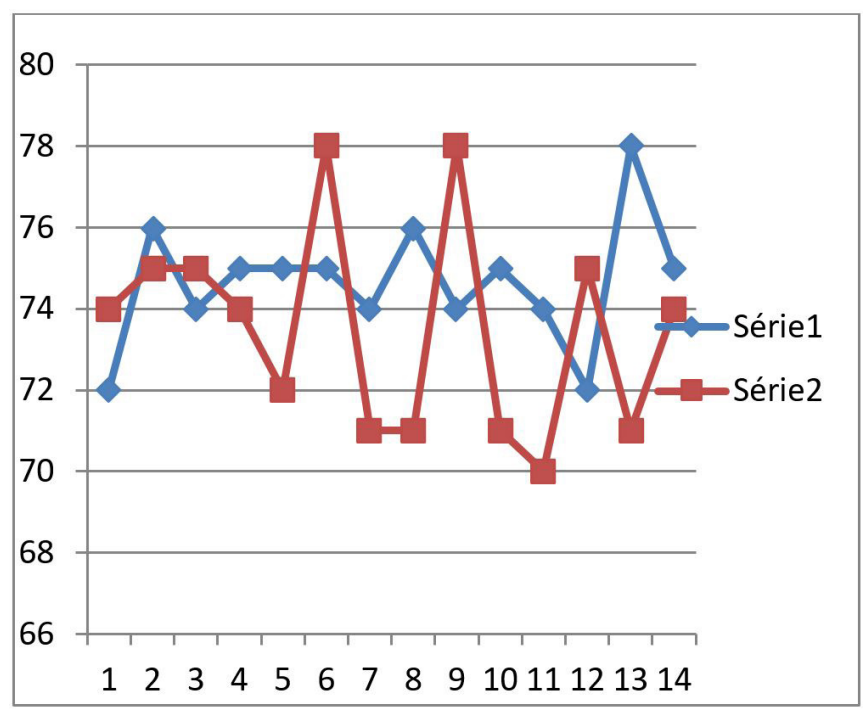

Figure 3. Pre group A and B result of Plantar Fasciitis Pain disability index

exercises with Theraband and Foot gym 3) on toes treadmill walking for 15 minutes.

\section{RESULTS:}

Baseline demographic data of both the groups were randomly done and were in an equal margin. Participants were primarily middle-aged (mean 40 years; SD \pm 10 ) and female $60 \%$. Intergroup pre value of both groups (figure 4) was recorded of PFPS. Intragroup pre and post values of group A and Group B were also statistically calculated and presented in the line graph (fig 4). FFI-R was measured Intra group pre and post values of group A (Table 1) and Group B (Table 2) were also statistically calculated and presented. Intergroup comparison was also calculated in table 3 and table 4. 


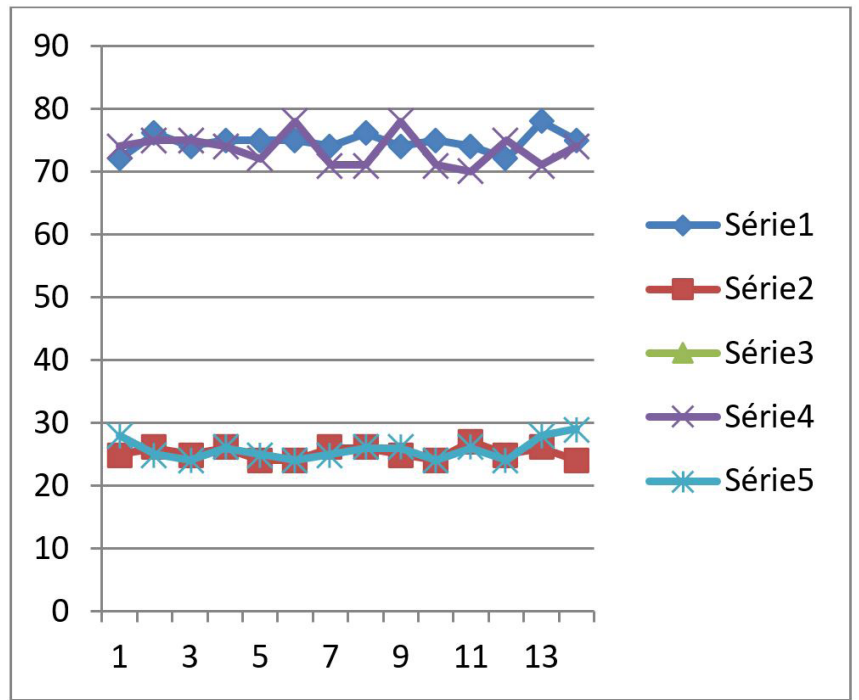

Figure 4. Pre and post result of Plantar Fasciitis Pain disability index

\section{DISCUSSION:}

Heel pain is the most common musculoskeletal pain any person experienced in his lifetime ${ }^{(27)}$, yet its etiology is poorly understood. There are many different physiotherapies or physical therapy related treatment for heel pain or plantar fasciitis ${ }^{(28-30)}$. The purpose of this study was to examine the effect of effect of MRT in the treatment of heel pain and to promote healing. In the present study effect of MRT was compared with the most commonly used conventional therapy that is with ICT followed by laser and strengthening exercises. The results demonstrate that MRT produces a statistically significant beneficial effect on 'first-step' pain compared with other conventional treatment. One reason for this trial found a statistically significant improvement in 'first-step' pain with MRT could be due to it being the symptom of plantar heel pain that is first notable to patients ${ }^{(31)}$. MRT is a new encroachment

Table 1. Intra group pre and post values of group A

\begin{tabular}{|c|c|c|c|c|c|c|c|c|}
\hline TREATMENT & ANLYSIS & MEAN & $\begin{array}{l}\text { STANDARD } \\
\text { DEVIATION }\end{array}$ & MEAN DIFF & SD DIFF & $\%$ OF CHANGE & Z TEST & P TEST \\
\hline \multirow[b]{2}{*}{ PAIN } & BEFORE & 37.07 & 1.92 & \multirow[b]{2}{*}{21.6} & \multirow[b]{2}{*}{5.05} & \multirow[b]{2}{*}{31.21} & \multirow[b]{2}{*}{0.96} & \multirow[b]{2}{*}{5.19} \\
\hline & AFTER & 25.5 & 16.25 & & & & & \\
\hline \multirow[b]{2}{*}{ STIFFNESS } & BEFORE & 27.5 & 1.82 & \multirow[b]{2}{*}{-2} & \multirow[b]{2}{*}{4.52} & \multirow[b]{2}{*}{-7.27} & \multirow[b]{2}{*}{1} & \multirow[b]{2}{*}{0.13} \\
\hline & AFTER & 29.5 & 16.25 & & & & & \\
\hline \multirow{2}{*}{ DIFFICULTY } & BEFORE & 76.07 & 1.35 & \multirow{2}{*}{48.64} & \multirow{2}{*}{4.11} & \multirow{2}{*}{63.94} & \multirow{2}{*}{5.5} & \multirow{2}{*}{1.42} \\
\hline & AFTER & 27.42 & 10.67 & & & & & \\
\hline \multirow{2}{*}{ ACTIVITY } & BEFORE & 30.07 & 1.35 & \multirow{2}{*}{13.86} & \multirow{2}{*}{4.11} & \multirow{2}{*}{46.08} & \multirow{2}{*}{0.55} & \multirow{2}{*}{0.6} \\
\hline & AFTER & 16.21 & 9.3 & & & & & \\
\hline \multirow{2}{*}{ SOCIAL } & BEFORE & 58.71 & 21.41 & \multirow[b]{2}{*}{63.24} & \multirow{2}{*}{2.14} & \multirow{2}{*}{108.011} & \multirow[b]{2}{*}{0} & \multirow[b]{2}{*}{0.4} \\
\hline & AFTER & 23.78 & 4.86 & & & & & \\
\hline
\end{tabular}

Table 2. Inter group pre and post values of group B

\begin{tabular}{|c|c|c|c|c|c|c|c|c|}
\hline TREATMENT & ANLYSIS & MEAN & $\begin{array}{l}\text { STANDARD } \\
\text { DEVIATION }\end{array}$ & MEAN DIFF & SD DIFF & $\begin{array}{c}\% \text { OF } \\
\text { CHANGE }\end{array}$ & Z TEST & P TEST \\
\hline PAIN & $\begin{array}{c}\text { BEFORE } \\
\text { AFTER }\end{array}$ & $\begin{array}{l}37.5 \\
39.5\end{array}$ & $\begin{array}{r}2.68 \\
16.25\end{array}$ & -8.93 & 7.63 & -12.76 & 1 & 0.017 \\
\hline STIFFNESS & $\begin{array}{c}\text { BEFORE } \\
\text { AFTER }\end{array}$ & $\begin{array}{l}30.11 \\
43.5\end{array}$ & $\begin{array}{r}4.84 \\
16.25\end{array}$ & -0.79 & 4.61 & 0 & 1 & 0.419 \\
\hline DIFFICULTY & $\begin{array}{c}\text { BEFORE } \\
\text { AFTER }\end{array}$ & $\begin{array}{l}76.21 \\
33.1\end{array}$ & $\begin{array}{l}1.6 \\
6.39\end{array}$ & -19.47 & 52.5 & 0 & 0.99 & 0.048 \\
\hline ACTIVITY & $\begin{array}{c}\text { BEFORE } \\
\text { AFTER }\end{array}$ & $\begin{array}{l}29.71 \\
14.71\end{array}$ & $\begin{array}{l}2.92 \\
1.06\end{array}$ & 29 & 52.11 & 97.59 & 0.14 & 0.018 \\
\hline SOCIAL & $\begin{array}{c}\text { BEFORE } \\
\text { AFTER }\end{array}$ & $\begin{array}{l}63.21 \\
25.21\end{array}$ & $\begin{array}{l}2.31 \\
1.45\end{array}$ & 122.38 & 219.51 & 193.6 & 0.03 & 0.46 \\
\hline
\end{tabular}


Table 3. Pre Intra group correlation between group A and B

\begin{tabular}{|c|c|c|c|c|c|c|c|c|}
\hline TREATMENT & ANLYSIS & MEAN & $\begin{array}{l}\text { STANDARD } \\
\text { DEVIATION }\end{array}$ & MEAN DIFF & SD DIFF & $\%$ OF CHANGE & Z TEST & P TEST \\
\hline \multirow{2}{*}{ PAIN } & BEFORE & 37.07 & 26.9 & \multirow{2}{*}{-0.8} & \multirow{2}{*}{1.99} & \multirow{2}{*}{-5.64} & \multirow{2}{*}{1} & \multirow{2}{*}{7.12} \\
\hline & BEFORE & 37.5 & 1.92 & & & & & \\
\hline \multirow{2}{*}{ STIFFNESS } & BEFORE & 27.5 & 1.82 & \multirow{2}{*}{-0.64} & \multirow{2}{*}{1.74} & \multirow{2}{*}{-2.14} & \multirow{2}{*}{1} & \multirow{2}{*}{0.48} \\
\hline & BEFORE & 30.1 & 4.83 & & & & & \\
\hline \multirow{2}{*}{ DIFFICULTY } & BEFORE & 76.07 & 1.35 & \multirow{2}{*}{-0.14} & \multirow{2}{*}{1.96} & \multirow{2}{*}{-0.24} & \multirow{2}{*}{1} & \multirow{2}{*}{0} \\
\hline & BEFORE & 76.21 & 1.6 & & & & & \\
\hline \multirow{2}{*}{ ACTIVITY } & BEFORE & 30.07 & 1.35 & \multirow{2}{*}{0.36} & \multirow{2}{*}{2.17} & \multirow{2}{*}{0.56} & \multirow[b]{2}{*}{1} & \multirow[b]{2}{*}{5.74} \\
\hline & BEFORE & 29.71 & 2.91 & & & & & \\
\hline \multirow{2}{*}{ SOCIAL } & BEFORE & 58.71 & 21.41 & \multirow[b]{2}{*}{0} & \multirow{2}{*}{1.75} & \multirow[b]{2}{*}{0} & \multirow[b]{2}{*}{1} & \multirow[b]{2}{*}{0.09} \\
\hline & BEFORE & 63.21 & 2.31 & & & & & \\
\hline
\end{tabular}

Table 4. Post Intra group correlation between group A and B

\begin{tabular}{|c|c|c|c|c|c|c|c|c|}
\hline TREATMENT & ANLYSIS & MEAN & $\begin{array}{l}\text { STANDARD } \\
\text { DEVIATION }\end{array}$ & MEAN DIFF & SD DIFF & $\begin{array}{c}\% \text { OF } \\
\text { CHANGE }\end{array}$ & Z TEST & P TEST \\
\hline \multirow{2}{*}{ PAIN } & AFTER & 25.5 & 16.25 & \multirow{2}{*}{78.43} & \multirow{2}{*}{133.58} & \multirow{2}{*}{98.01} & \multirow{2}{*}{0.04} & \multirow{2}{*}{0.03} \\
\hline & AFTER & 39.5 & 16.25 & & & & & \\
\hline \multirow{2}{*}{ STIFFNESS } & AFTER & 29.5 & 16.25 & \multirow{2}{*}{-18.64} & \multirow{2}{*}{115.47} & \multirow{2}{*}{-22.58} & \multirow{2}{*}{0.85} & \multirow{2}{*}{0.18} \\
\hline & AFTER & 43.5 & 16.25 & & & & & \\
\hline \multirow{2}{*}{ DIFFICULTY } & AFTER & 27.43 & 10.67 & \multirow{2}{*}{-7.21} & \multirow{2}{*}{13.51} & \multirow{2}{*}{-11.22} & \multirow{2}{*}{1} & \multirow{2}{*}{0.03} \\
\hline & AFTER & 33.1 & 6.38 & & & & & \\
\hline \multirow{2}{*}{ ACTIVITY } & AFTER & 16.21 & 9.31 & \multirow{2}{*}{2.71} & \multirow{2}{*}{6.31} & \multirow{2}{*}{10.19} & \multirow{2}{*}{1} & \multirow{2}{*}{0.03} \\
\hline & AFTER & 14.71 & 1.06 & & & & & \\
\hline \multirow{2}{*}{ SOCIAL } & AFTER & 23.79 & 4.86 & \multirow{2}{*}{0.64} & \multirow{2}{*}{2.06} & \multirow{2}{*}{1.42} & \multirow{2}{*}{1} & \multirow{2}{*}{0.04} \\
\hline & AFTER & 25.21 & 1.45 & & & & & \\
\hline
\end{tabular}

which uses the concept of vibromassage to restores the good tissue resonance. The lifting action produced by the oscillator as a horizontal micro extension movement is transferred to the inner organs, tissues, and bones that allow the cell metabolism of the tissue to be reactivated with depth-effective rhythmical micro-extensions. Further, the contracted areas of the musculature at inductively relaxed (circulation > oxygen $>$ ATP $>$ dissolution of the tension) ${ }^{(32)}$. Another reason patient responded to first1 step reduced pain could be due to increased ankle dorsiflexion, calf endurance and relived occupational lower limb stresses are the likely causes of the heel pain. A study was done to evaluate the effect of massage and MRT in young women on the peripheral blood circulation. In this study MRT was applied to the left lower extremity for a single 30-minute session. The popliteal and the posterior tibial arteries were measured with color Doppler ultrasonography by the radiologist. Results concluded that MRT caused a more prominent increase in the amount of blood flow in the popliteal and in the posterior tibial artery than did massage ${ }^{(33)}$. Strengthening exercise after the MRT showed significant improvement in maintaining the intrinsic foot musculature strength and further increasing the foot and ankle function. A study was done to evaluate the literature investigating strength training interventions in the treatment of plantar fasciitis and improving intrinsic foot musculature strength supported the present study. In the literature review, the study stated that the foot exercises, toe flexion against resistance and minimalist running shoes may contribute to improved intrinsic foot musculature function. It also aids in a reduction of pain and improvements in function ${ }^{(34)}$. Another study aimed to investigate high-load strength training consisted of unilateral heel raises with a towel inserted under the toes was conducted with a primary outcome as the FFI at 3 months. Purpose of this case series was to describe physical therapist decision-making of individualized multimodal treatment. The study concluded that high-load strength training may aid in a quicker reduction in pain and improvements in function ${ }^{(35)}$. 


\section{LIMITATIONS:}

The findings of this trial need to be viewed in light of some limitations. Firstly the study subjects were taken from a limited source and secondly tracking of the therapeutic effect was not done for the longer duration, hence limited to mention about the period of lasting effect.

\section{CONCLUSION:}

The patients improved with both treatment strategies; however, MRT with strengthening exercise was found to be superior ICT and laser with strengthening exercises to for first step pain, physical health, and satisfaction of the patients.

\section{Acknowledgement:}

The authors would like to thank Likhil Kavalekar for his assistance in detailed statistical recording and data filtering.

\section{CONFLICT OF INTEREST}

Nothing to declare

\section{REFERENCES:}

1. Landorf KB. Plantar heel pain and plantar fasciitis. BMJ Clin Evid. 2015 Nov 25;2015. pii: 1111.

2. DeMaio M, Paine R, Mangine RE, Drez D. Plantar fasciitis. Orthopedics. 1993; 16(10): 1153-63.

3. Tu P. Heel Pain: Diagnosis and Management. American family physician. 2018; 97(2): 86-93.

4. Zöllner AM, Pok JM, McWalter EJ, Gold GE, Kuhl E. On high heels and short muscles: A multiscale model for sarcomere loss in the gastrocnemius muscle. Journal of theoretical biology. 2015; 365: 301-10.

5. Lourdes RK, Ram GG. Incidence of calcaneal spur in Indian population with heel pain. International Journal of Research in Orthopaedics. 2016; 2(3): 173.

6. Thomas MJ, Roddy E, Zhang W, Menz HB, Hannan MT, Peat G.M. The population prevalence of foot and ankle pain in middle and old age: a systematic review. Pain. 2011; 152(12): 2870-80.

7. Chatterton BD, Muller S, Roddy E. Epidemiology of Posterior Heel Pain in the General Population: Cross-Sectional Findings From the Clinical Assessment Study of the Foot. Arthritis care \& research. 2015; 67(7): 996-1003.

8. Sullivan J, Burns J, Adams R, Pappas E, Crosbie J. Plantar heel pain and foot loading during normal walking. Gait \& posture. 2015; 41(2): 688-93.

9. Jensen, MP, Moore, MR, Bockow, TB, Ehde, DM, Engel, JM. Psychosocial factors and adjustment to chronic pain in persons with physical disabilities. A systematic review. Arch Phys Med Rehabil. 2011 Jan; 92(1):146-60.

10. Rogers JA, Wilson A, Laslett LL, Winzenberg TM. Physical interventions (orthoses, splints, exercise and manual therapy) for treating plantar heel pain. The Cochrane Library. 2016.

11. Rogers JA, Wilson A, Laslett LL, Winzenberg TM. Physical interventions (orthoses, splints, exercise and manual therapy) for treating plantar heel pain. The Cochrane Library. 2015; 24: 135-42.

12. Fischell SR, Fischell RE, inventors; Zygood LLC, assignee. Three-coil magnetic pulsations system for the treatment of foot pain. United States patent US 9,849,302. 2017.

13. Cotchett MP, Munteanu SE, Landorf KB. Effectiveness of trigger point dry needling for plantar heel pain: a randomized controlled trial. Physical therapy. 2014; 94(8): 1083-94.

14. International Medical Technologies. [website] Life is fundamentally inseparable from process. Living processes manifest themselves in rhythm [access in Sept 2, 2018] Available in: http://marhythe.in/
15. Dr. Randoll Institute [website] How Matrix Rhythm Therapy (MaRhyThe) Work [access in Sept 4, 2018] Available in: https://www.dr-randoll-institut. de/en/so-wirkt-die-matrix-rhythmus-therapie-marhythe/

16. Treloar Physiotherapy Clinic[website] How Laser Therapy Works [access in Sept 6, 2018 ] Available in: https://www.treloarphysio.com/blog/articles/ physiotherapyarticles/lasertherapy/

17. Tunnel C. About Low Level Laser Therapy. 1999.

18. Enwemeka CS, Parker JC, Dowdy DS, Harkness EE, Harkness LE, Woodruff LD. The efficacy of low-power lasers in tissue repair and pain control: a metaanalysis study. Photomedicine and Laser Therapy. 2004; 22(4): 323-9.

19. PtHealth [website] Interferential Current [access in sept 10, 2018] Available in: Therapyhttps://www.pthealth.ca/service/interferential-current-therapy/\#

20. Johnson BG, Rhodes DA, inventors; Alan Neuromedical Tech LLC, Dynatronics Corp, assignee. Interferential current treatment apparatus. United States patent US 6,826,429. 2004 Nov 30.

21. Razzano C, Carbone S, Mangone M, lannotta MR, Battaglia A, Santilli V. Treatment of Chronic Plantar Fasciitis with Noninvasive Interactive Neurostimulation: A Prospective Randomized Controlled Study. The Journal of Foot and Ankle Surgery. 2017; 56(4): 768-72.

22. Willis B, Lopez A, Perez A, Sheridan L, Kalish S. Pain scale for plantar fasciitis. The Foot and Ankle Online Journal. 2009; 2(5): 3-9.

23. Ratna ST, Dowle P, Prasad VBN, Paruchuri RK. Effect of kinesio taping in adjunct to conventional therapy in reducing pain and improving functional ability in individuals with plantar fasciitis a randomized controlled trial. International Journal of Physiotherapy. 2015; 2(4): 587-93.

24. Budminan-Mak, E, Conrad KJ, Roach, K. E. The Foot Function Index: A measure of foot pain and disability. Journal of Clinical Epidemiology. 1991; 44(6): 561-70.

25. Budiman-Mak E, Conrad K, Stuck R, Matters M. Theoretical model and Rasch analysis to develop a revised Foot Function Index. Foot \& Ankle International. 2006; 27(7): 519-27.

26. Radford JA, Landorf KB, Buchbinder R, Cook C. Effectiveness of low-Dye taping for the short-term treatment of plantar heel pain: a randomised trial. BMC musculoskeletal disorders. 2006; 7(1): 64.

27. Digiovanni BF, Nawoczenski DA, Lintal ME, Moore EA, Murray JC, Wilding GE, Baumhauer JF. Tissue-specific plantar fascia-stretching exercise enhances outcomes in patients with chronic heel pain: a prospective, randomized study. JBJS. 2003; 85(7): 1270-7.

28. Hoskins W, McHardy A, Pollard H, Windsham R, Onley R. Chiropractic treatment of lower extremity conditions: a literature review. Journal of manipulative and physiological therapeutics. 2006; 29(8): 658-71.

29. Johnson BG, Rhodes DA, inventors; Alan Neuromedical Tech LLC, Dynatronics Corp, assignee. Interferential current treatment apparatus. United States patent US 6,826,429. 2004 Nov 30.

30. Taspinar F, Aslan UB, Sabir N, Cavlak U. Implementation of Matrix Rhythmus Therapie and conventional massage in young females and comparison of their acute effects on circulation. The Journal of Alternative and Complementary Medicine. 2013; 19(10): 826-32.

31. Ulrich GR, Friedrich FH. Cell biological basics, theory and practice; pt zeitschrift fur physiotherapeuten. 2009; 6(61).

32. Taspinar F, Aslan UB, Sabir N, Cavlak U. Implementation of matrix rhythm therapy and conventional massage in young females and comparison of their acute effects on circulation. The Journal of Alternative and Complementary Medicine. 2013; 19(10): 826-32.

33. Huffer D, Hing W, Newton R, Clair M. Strength training for plantar fasciitis and the intrinsic foot musculature: A systematic review. Physical Therapy in Sport. 2017; 24: 44-52.

34. Rathleff MS, Mølgaard CM, Fredberg U, Kaalund S, Andersen KB, Jensen TT, Aaskov S, Olesen JL. High-load strength training improves outcome in patients with plantar fasciitis: A randomized controlled trial with 12-month follow-up. Scandinavian journal of medicine \& science in sports. 2015; 25(3): 292-300.

35. Rathleff MS, Mølgaard CM, Fredberg U, Kaalund S, Andersen KB, Jensen TT et al. High-load strength training improves outcome in patients with plantar fasciitis: A randomized controlled trial with 12-month follow-up. Scand J Med Sci Sports. 2015 Jun;25(3):e292-300. 